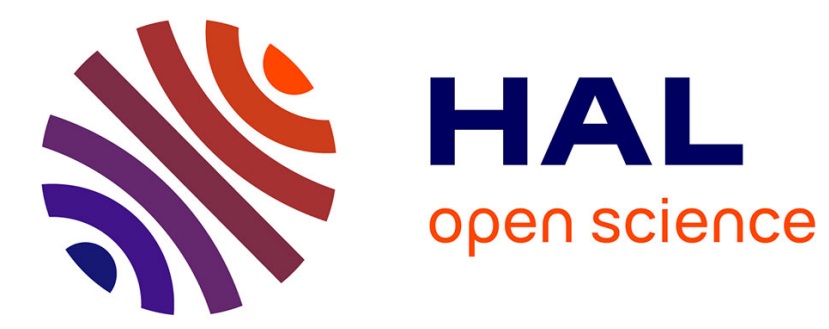

\title{
SPIN RELAXATION AND BREIT-RABI SPECTRA OF CUBIC Yb SALT
}

G. Shenoy, L. Asch, J. Friedt, B. Dunlap

\section{To cite this version:}

G. Shenoy, L. Asch, J. Friedt, B. Dunlap. SPIN RELAXATION AND BREIT-RABI SPECTRA OF CUBIC Yb SALT. Journal de Physique Colloques, 1974, 35 (C6), pp.C6-425-C6-427. 10.1051/jphyscol:1974684 . jpa-00215841

\section{HAL Id: jpa-00215841 https://hal.science/jpa-00215841}

Submitted on 1 Jan 1974

HAL is a multi-disciplinary open access archive for the deposit and dissemination of scientific research documents, whether they are published or not. The documents may come from teaching and research institutions in France or abroad, or from public or private research centers.
L'archive ouverte pluridisciplinaire HAL, est destinée au dépôt et à la diffusion de documents scientifiques de niveau recherche, publiés ou non, émanant des établissements d'enseignement et de recherche français ou étrangers, des laboratoires publics ou privés. 


\title{
SPIN RELAXATION AND BREIT-RABI SPECTRA OF CUBIC Yb SALT $\left(^{*}\right)$
}

\author{
G. K. SHENOY, L. ASCH and J. M. FRIEDT \\ Laboratoire de Chimie Nucléaire, 67037 Strasbourg Cedex; France \\ B. D. DUNLAP \\ Argonne National Laboratory, Argonne, Illinois 60439, U. S. A.
}

\begin{abstract}
Résumé. - Le spectre Mössbauer de ${ }^{170} \mathrm{Yb}$ dans le composé cubique $\mathrm{Cs}_{2} \mathrm{NaYbCl}_{6}$ a été mesuré en fonction de la température et d'un champ magnétique externe. Le spectre hyperfin du niveau fondamental $\Gamma_{6}$ est fortement influencé par de faibles champs magnétiques. Les détails sont décrits par un diagramme de Breit-Rabi. La fréquence de relaxation de spin de $\mathrm{Yb}^{3+}$ dépend du champ externe mais est indépendante de la température jusqu'à $20 \mathrm{~K}$.
\end{abstract}

\begin{abstract}
The Mössbauer spectrum of ${ }^{170} \mathrm{Yb}$ in cubic $\mathrm{Cs}_{2} \mathrm{NaYbCl}_{6}$ has been measured as a function of temperature and external field. The hyperfine spectrum due to $\Gamma_{6} \mathrm{CEF}$ level, which is the ground state in this compound, is strongly influenced by small magnetic fields. The details are described using a Breit-Rabi diagram. The spin relaxation time of $\mathrm{Yb}^{3+}$ is strongly dependent on the external field but is independent of temperature up to $20 \mathrm{~K}$.
\end{abstract}

We have recently shown from the Mössbauer studies of ${ }^{170} \mathrm{Yb}$ in $\mathrm{Cs}_{2} \mathrm{NaYbCl}_{6}$ that the $\mathrm{Yb}^{3+}$ ion experiences a cubic crystalline electric field (CEF) in this compound [1]. From the observed paramagnetic hyperfine structure it was established that the ground CEF level is a $\dot{\Gamma}_{6}$ state, in agreement with susceptibility measurements [2]. We report in the present work the study of relaxation spectra as a function of temperature and of applied magnetic field.

The primary relaxation mechanisms we are concerned with in such an undiluted chemical compound arise through spin-lattice and spin-spin coupling. The former mechanism is strongly temperature dependent [3-4], while the latter can be dependent on magnetic field [5]. The experimentally measured relaxation time $(\tau)$ is then related to the spin-lattice $\left(\tau_{1}\right)$ and to the spinspin $\left(\tau_{s}\right)$ relaxation times through the relation

$$
\left(\tau^{-1}\right)=\left(\tau_{1}\right)^{-1}+\left(\tau_{\mathrm{s}}\right)^{-1}
$$

$\tau_{1}$ is dependent on various phonon scattering mechanisms, viz. direct, Raman and Orbach processes. The value of $\tau_{\mathrm{s}}$ is mainly governed by the distance between the paramagnetic atoms in the lattice. In the case $\tau_{1}$ and $\tau_{\mathrm{s}}$ are of comparable magnitudes, $\tau$ itself would be temperature dependent. Such a situation is rather common in rare-earth compounds as has been demonstrated in the case of $\mathrm{YbCl}_{3}, 6 \mathrm{H}_{2} \mathrm{O}$ [6].

We have measured the temperature dependence of Mössbauer resonance spectra of $\mathrm{Cs}_{2} \mathrm{NaYbCl}_{6}$ between

(*) Work performed in part under the auspices of the U.S. Atomic Energy Commission.
1.6 and $40 \mathrm{~K}$ using the $84 \mathrm{keV}$ transition in ${ }^{170} \mathrm{Yb}$. In figure $1 a$ we show the spectrum measured at $4.2 \mathrm{~K}$. The asymmetric pattern with two resonance lines is characteristic of the $\Gamma_{6}$ CEF level [1]. The shape of the spectrum did not change up to $20 \mathrm{~K}$. A rapid decrease in the resonance fraction did not permit discernable measurements above $20 \mathrm{~K}$.

The analysis of the paramagnetic relaxation spectra of the $\Gamma_{6}$ state with isotropic hyperfine coupling can be done using Hirst's theory [7]. We have however preferred to use the closed form equations provided by Gonzalez-Jimenez et al. [8]. The solid curves in figure $1 a$ show the least-squares fit to the data using this theory. The resulting relaxation time was found to be fairly constant in the temperature range from 1.6 to $20 \mathrm{~K}$, with a value of $5 \times 10^{-9} \mathrm{~s}$.

In order to understand the relaxation spectra of this compound in applied magnetic fields one has to describe the influence of the field on the static hyperfine structure of the $\Gamma_{6} \mathrm{CEF}$ level. Small fields lift the degeneracy of the two hf components shown in figure $1 a$, so that 20 transitions become possible. The field dependence given by the hamiltonian

$$
\mathscr{H}=A_{\mathrm{s}}\left[\bar{I} \cdot \bar{S}-h S_{z}\right]
$$

with $h=g \mu_{\mathrm{B}} H_{\text {ext }} / A_{\mathrm{s}}$, and $A_{\mathrm{s}}=-10.9 \pm 0.1 \mathrm{~mm} / \mathrm{s}$, has been depicted using a Breit-Rabi diagram (Fig. 2) [9]. Figure 2 represents the energies and the intensities of the 20 transitions as a function of the external field. The details relative to such a diagram are given in [10]. The angular distribution of the various hf transitions however limits the number of observable 


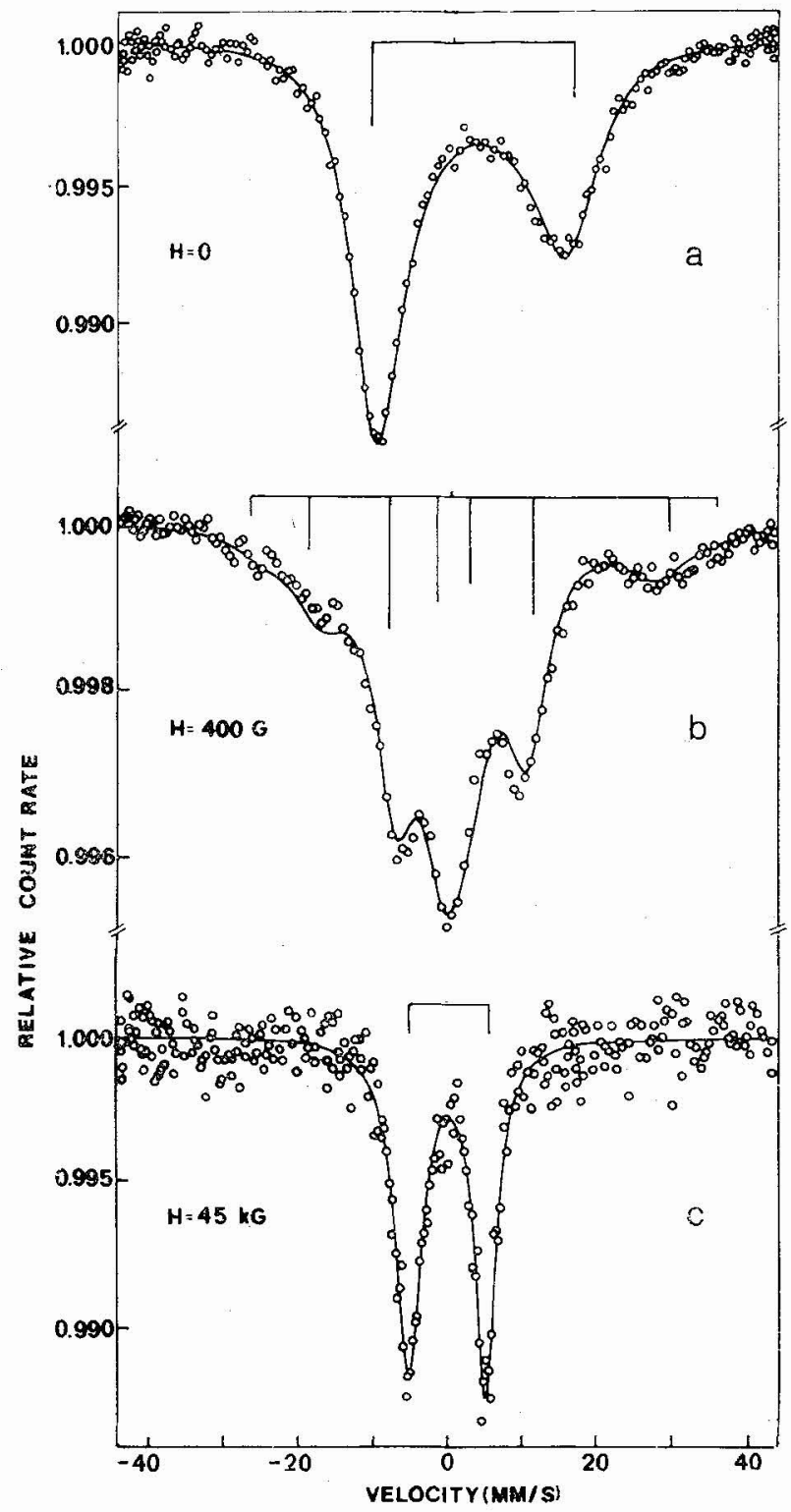

Fig. 1. - Mössbauer spectra of $\mathrm{Cs}_{2} \mathrm{NaYbCl}_{6}$ at $4.2 \mathrm{~K}$ for different external fields : a) $0 \mathrm{kG}, b$ ) $0.4 \mathrm{kG}, c) 45 \mathrm{kG}$.

ones to eight $\left(8^{-}, 3^{+}, 4^{-}, 7^{+}, 9^{-}, 2^{+}, 6^{+}, 5^{-}\right.$in Fig. 2$)$ if the external field is parallel to the gamma ray absorption direction. With increasing field, four $\left(9^{-}, 5^{-}, 2^{+}\right.$, $6^{+}$) of these gradually reduce in intensity. In very high fields $(\sim 30 \mathrm{kG})$, the remaining four transitions merge into two (see Fig. 2) and the result is typical of paramagnetic hyperfine spectra with $g_{z} \neq 0, g_{x}=g_{y}=0$ observed parallel to the $z$ axis. Increasing the field basically results in gradually decoupling the effective spin $S=\frac{1}{2}$ of the $\Gamma_{6}$ level and the nuclear spin $I$; finally in high fields we reach the Paschen-Back region where the electron-nuclear system is completely decoupled. It must be pointed out that the isotropic character essential to a Breit-Rabi description of the system can be perturbed by the mixing of higher CEF levels in an external field. However this is not the situa-
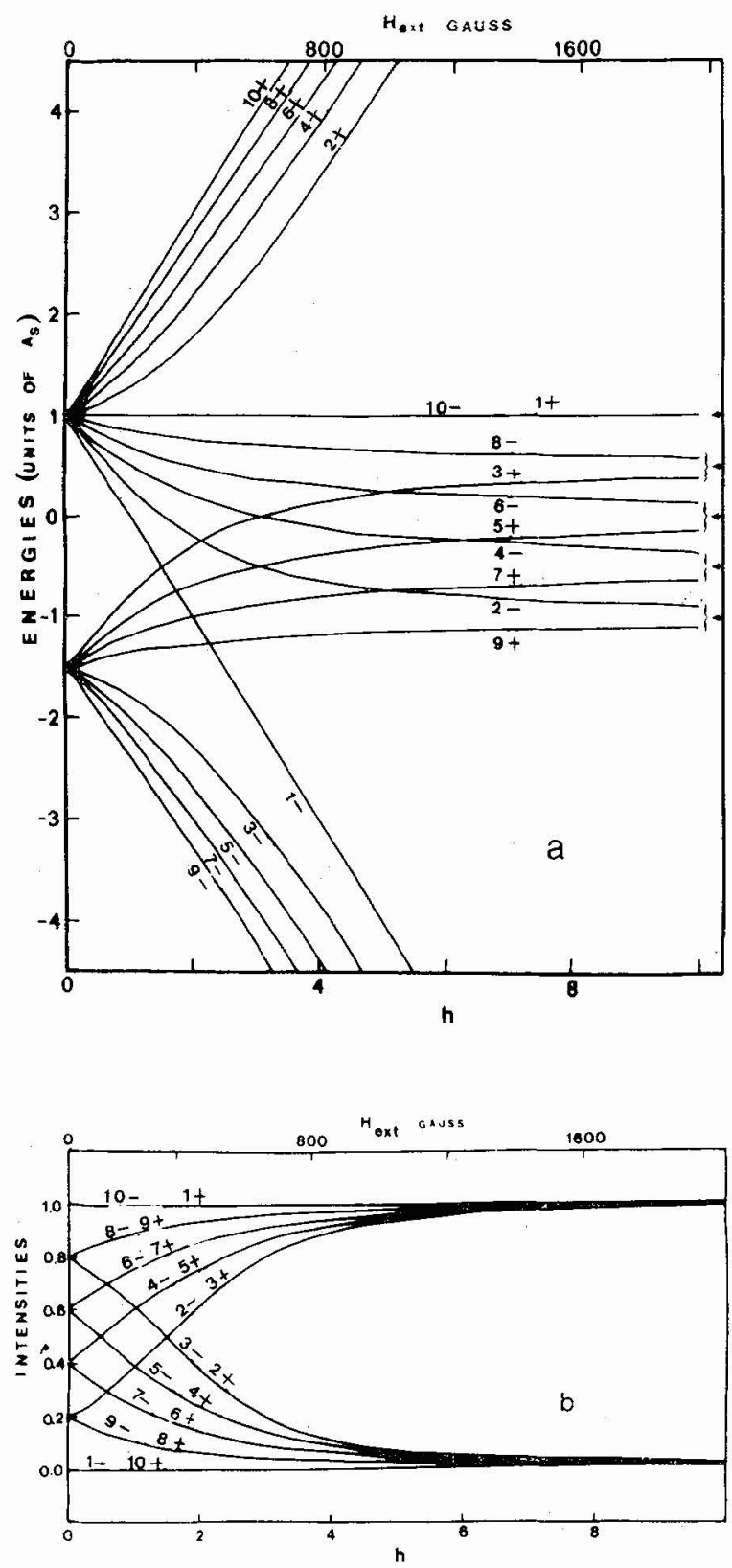

Frg. 2. - Breit-Rabi diagram : a) energies and b) intensities of the Mössbauer transitions as a function of external magnetic field.

tion in $\mathrm{Cs}_{2} \mathrm{NaYbCl}_{6}$ in which the first excited $\mathrm{CEF}$ level is a few hundred degrees above the $\Gamma_{6}$ level [11].

In an isotropic electron-nuclear coupled system the hyperfine energies depend on the applied field, which leads to a field dependent nuclear correlation time $\left(\tau_{c}\right)$. In order to study the variation of $\tau$ with field one has thus to include the dependence of hyperfine frequencies on the field in the relaxation theory. Such a theory is available from Gonzalez-Jimenez et al. [8] and we have used it to least-squares fit the data obtained in small fields (see for example, Fig. 1b). The analysis of the spectrum measured at $45 \mathrm{kG}$ (Fig. 1c) is 


\section{TABLE I}

Spin relaxation rate for $\mathrm{Yb}^{3+}$ in $\mathrm{Cs}_{2} \mathrm{NaYbCl}_{6}$ at various temperatures and external magnetic fields

\begin{tabular}{|c|c|c|}
\hline $\begin{array}{c}\text { Temperature } \\
\text { K }\end{array}$ & $\begin{array}{l}H_{\mathrm{cxt}} \\
\mathrm{kG}\end{array}$ & $\begin{array}{c}\tau \\
\text { ns }\end{array}$ \\
\hline 1.6 & 0 & $4.9 \pm 0.5$ \\
\hline 4.2 & 0 & $4.7 \pm 0.5$ \\
\hline 20 & 0 & $4.5 \pm 0.8$ \\
\hline 1.6 & 0.30 & $6 \pm 1$ \\
\hline 4.2 & 0.30 & $6 \pm 1$ \\
\hline 4.2 & 0.40 & $8 \pm 2$ \\
\hline 4.2 & 0.85 & $12 \pm 3$ \\
\hline 4.2 & 45 & $>\overline{15}$ \\
\hline
\end{tabular}

however done using an effective field relaxation theory [3] and including a Boltzmann distribution over the electronic levels. We find that the resulting relaxation times depend on the field and increase with increasing field. In fact the situation is such that the spectrum in $400 \mathrm{G}$ may be considered nearly static i. e. $\tau \gg \tau_{\mathrm{c}}$. In figure $1 b$ we have shown the 8 transitions with appropriate intensities as calculated from figure 2 for this particular case. The typical relaxation times with and without the field are larger than $\tau_{\mathrm{c}}\left(\approx 10^{-10} \mathrm{~s}\right)$. Hence the values of $\tau$ deduced from the analysis (and given in Table I) are susceptible to large errors.

$\mathrm{In}_{2} \mathrm{NaYbF}_{6}, \tau$ is of the order of $10^{-9} \mathrm{~s}$ at $4.2 \mathrm{~K}$ in zero applied field so that the influence of field can be more quantitatively studied in this case [12].

In conclusion one may point out that the observed variation in $\tau$ with field is a manifestation of the field dependence of $\tau_{\mathrm{s}}$; however as $\tau_{\mathrm{s}}$ decreases it may become comparable to $\tau_{1}$ so that the nature of the $\tau$ dependence on field cannot be solely associated with $\tau_{\mathrm{s}}$.

\section{References}

[1] Shenoy, G. K., Poinsot, R., Asch, L., Friedt, J. M. and DunlaP, B. D. (to be published).

[2] Karraker, D. G., J. Chem. Phys. 55 (1971) 1084.

[3] Wickmann, H. H. and Wertheim, G. K., in Chemical Applications of Mössbauer Spectroscopy, Eds Goldanskii V. I. and Herber R. H. (Academic Press, N. Y.) 1968 pp. 548-621.

[4] Blume, M., Phys. Rev. Lett. 18 (1967) 305.

[5] CAspers, W. J., Theory of Spin Relaxation (Interscience, N.Y.) 1964

[6] Dunlap, B. D., Shenoy, G. K. and Kalvius, G. M., Phys. Rev. (in press).
[7] Hirst, L. L., J. Phys. Chem. Solids 31 (1970) 655

[8] Gonzalez-Jimenez, F., Imbert, P. and Hartman-BouTrON, F., Phys. Rev. B 9 (1974) 95.

[9] Breit, G. and Rabi, I. I., Phys. Rev. 38 (1931) 2082.

[10] Shenoy, G. K., Stöhr, J., Wagner, W., Kalvius, G. M. and DUNLAP, B. D. (to be published).

[11] Although in reference [2] the separation of excited state is given to be $85 \mathrm{~K}$, a careful reanalysis of the susceptibility data yields this separation to be at least $450 \mathrm{~K}$.

[12] Dunlap, B. D., Davidson, G. R., Eibschutz, M., GugGENHEIM, H. J. and SHERWOOD, R. C., J. Physique Colloq. 35 (1974) C 6. 